\title{
DAKAR: DEL MERCADO A LA COCINA Y A LA MESA. LA COMIDA, SUS RELACIONES Y SUS SÍMBOLOS
}

\author{
MARÍA GUADALUPE AGUILAR ESCOBEDO \\ El Colegio de México
}

Kuy jaay kamaate doo bëré: boo ca dëggee mu toj. Aquel que vende tomate, no debe combatirse.

Proverbio LÉBOU ${ }^{1}$

\section{Introducción}

Cada sociedad adapta el acto de comer a sus estructuras. El presente artículo tiene como objetivo destacar la importancia de la comida en la vida contemporánea y cotidiana de los habitantes de la capital senegalesa, Dakar.

La alimentación es el eje central de este artículo, el cual pretende mostrar cómo las actividades simbólicas ligadas a la adquisición de la comida, su preparación, rituales, restricciones y etiqueta, fortalecen las identidades de género en torno de la "mesa”. Si la urbanización de la región, la economía y el ritmo de vida han cambiado los patrones de consumo, cacaso éstos han modificado el acto de socialización y la formalización de los alimentos?

Con base en la observación y la convivencia alrededor de los alimentos pueden descifrarse ciertas transcripciones en las que se impregnan los valores religiosos, culturales y sociales del país.

Este artículo fue recibido por la dirección de la revista el 15 de mayo de 2013 y aceptado para su publicación el 29 de septiembre de 2013.

${ }^{1}$ Jacqueline Cribier, Martine Dreyfus y Mamadou Gueye, Léebu, proverbes wolof, París, Edicef, 1986. 
Senegal es conocido como el país de la teranga. Teranga, en lengua wolof, significa hospitalidad, y dentro de la hospitalidad compartir la comida sigue siendo un acto social. "La comida es también la ocasión de [...] distribuir y dar".?

El artículo se divide en tres partes con el objetivo de observar cómo se construyen las identidades de los hombres y las mujeres en torno de la alimentación desde la perspectiva de género. Género es

[...] un elemento constitutivo de las relaciones sociales basadas en las diferencias que distinguen los sexos y una forma primaria de relaciones significantes de poder. Los cambios en la organización de las relaciones sociales corresponden siempre a cambios en las representaciones del poder, pero la dirección del cambio no es necesariamente en un solo sentido. ${ }^{3}$

La primera parte de este artículo aborda el mercado como el lugar de los insumos y los ingresos familiares de las vendedoras y su función social. Durante el verano de 2010, en una estancia de investigación, realicé varias entrevistas en profundidad con mujeres de diversos mercados de la capital y zona conurbada. El objetivo fue recolectar sus testimonios de vida; se recabaron datos sobre la economía familiar, la estructura familiar, la religión y el código de la familia. Algunos testimonios serán citados. ${ }^{4}$

La segunda parte del artículo trata sobre el papel diferenciado de hombres y mujeres en la preparación de los alimentos y sus rituales.

La tercera parte describe el espacio designado como la mesa, sus reglas y sus símbolos al momento de compartir los alimentos.

${ }^{2}$ Robin Fox, "Food and Eating: An Anthropological Perspective", Oxford, Social Issues Research Centre, 2003, p. 1.

${ }^{3}$ Joan Scott, "Gender: A Useful Category of Historical Analysis", The American Historical Review, vol. 91, núm. 5, p. 1067.

${ }^{4}$ Estos testimonios fueron recabados en wolof (la lengua nacional del país), y se contó con el apoyo de Bibiane Manga para la traducción francés-wolof-francés. En el trabajo de campo en el mercado de Tilène el apoyo fue de Leyty Diagne. 


\section{E1 mercado}

\section{El espacio físico}

El mercado en Dakar es un espacio público; puede estar en un lugar establecido o ser itinerante. Sus pobladores acuden a ellos de manera cotidiana ${ }^{5}$ para abastecerse de productos para la alimentación, el hogar, la higiene, la vestimenta y la seducción.

Dakar cuenta con varios mercados especializados para cubrir las necesidades cotidianas y específicas de sus habitantes. La venta de pescado, frutas y legumbres, en su mayoría se encuentra a cargo de las mujeres, quienes a través de esta actividad generan un ingreso familiar monetario; además, tienen la posibilidad de efectuar un trueque de mercancías o de llevar a casa lo que no han vendido.

Las 20 mujeres entrevistadas citaron la alimentación como el gasto prioritario de su lista.

Se visitó el mercado fijo de Tilène, el cual está dividido en dos partes: una dedicada a los productos de uso cotidiano, del hogar y de lujo, y otra dedicada a los abarrotes y los productos alimenticios. Tilène cuenta con locales fijos en un espacio cerrado y puestos itinerantes alrededor del mercado; las vendedoras en los espacios móviles improvisan puestos sobre cubetas, las cuales son instaladas como mesas exhibidoras de verduras o pescado, lo que las obliga a estar de pie mucho tiempo.

Las comerciantes del otro mercado de legumbres, ubicado en Thiaroye, y de los mercados de pescados, ubicados en Soumbédioune y Yoff Tangor, tienen una mayor movilidad en cuanto a puntos de venta. Las vendedoras de Tilène, Thiaroye y Soumbédioune viven en zonas alejadas de su lugar de venta.

${ }^{5}$ De acuerdo con una encuesta publicada por Fatou Ndoye et al. (Évolution des styles alimentaires à Dakar, Montpellier, CIRAD, 2001, p. 48), 75.4\% de los dakareses van al mercado diariamente; $8.7 \%$, de dos a seis veces por semana; $8.3 \%$, una vez a la semana; $5.9 \%$, cada quincena; $1 \%$, cada mes y 0.6 no dio respuesta. 
Los mercados de pescado

El platillo típico del país es el thieboudienne (o ceebu jën), ${ }^{6}$ cuya base es el arroz acompañado de verduras y pescado. Su "naturaleza tradicional" es síntesis de un proceso construido y de invención de la identidad. El arroz fue un cultivo implantado por la colonia francesa para asegurar sus provisiones en la metrópoli; sin embargo, el pescado ha estado presente a lo largo de la historia previa y posterior a la colonización.

Dakar cuenta con salida al océano Atlántico; la pesca es la principal actividad económica en el país ${ }^{7}$ y está fuertemente marcada por una división sexual del trabajo, pues está reservada para los hombres, quienes en su mayoría pertenecen a los grupos étnicos wolof y lebou. Ellos enfrentan cotidianamente dificultades, como el encarecimiento de los recursos para salir a pescar y mantener el pescado fresco, la competencia desleal de los navíos industriales y la falta de una organización interna.

Los pescadores salen por la madrugada y la mañana a mar abierto en sus piraguas (de motor o remo) y al atardecer vuelven con la pesca del día. A su regreso, sus esposas y demás mujeres se acercan para escoger el pescado que será vendido por la tarde o al día siguiente.

Las vendedoras trabajan diario y tienen dos turnos: el primero inicia a las diez de la mañana y termina a las dos de la tarde; el segundo turno comienza a las cinco de la tarde y termina a media noche. Las mujeres están a cargo de la venta de pescado en sus puestos y deben estar al pendiente de su conservación, para lo cual utilizan un poco de hielo cuando hay recursos para comprarlo y, si no, lo rocían con agua. Algunas mujeres sin fondos propios llegan solamente para limpiar el pescado y obtener un ingreso.

${ }^{6} \mathrm{La}$ comida senegalesa es muy variada, es síntesis geográfica e histórica de las regiones que integran el país, sus grupos étnicos, las ex colonias que alguna vez gobernaron y la movilidad internacional. Como ejemplos se tiene el pollo yassa (pollo con cebolla y limón), el mafé (arroz blanco acompañado con una salsa generosa hecha de pasta de cacahuate, a la cual se le puede agregar legumbres y carne) y el couscous (sémola de mijo con legumbres y carne).

${ }^{7}$ Después del agotamiento del modelo económico, dependiente del cacahuate y el fosfato, la pesca constituye la principal fuente de ingresos en el país. 
Fото 1. Las piraguas matriculadas de Soumbédioune.

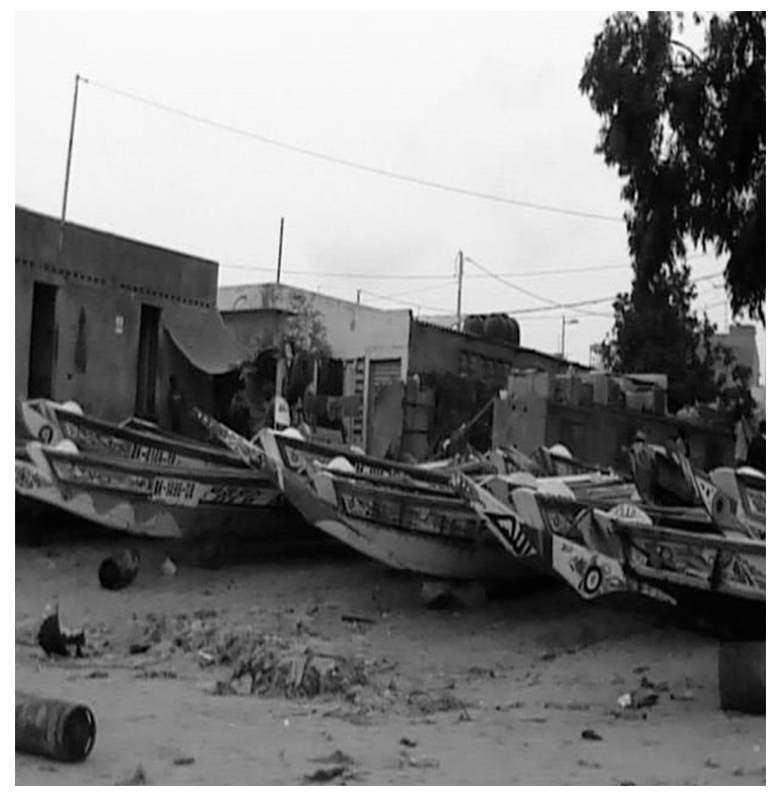

Cuando la noche avanza y los clientes han disminuido, las vendedoras comienzan a abaratar la mercancía, lo cual implica una venta a pérdida donde sólo se recupera el precio justo del pescado o una cantidad menor.

Una vez que la venta ha fracasado, las vendedoras terminan por llevar los productos a casa para la alimentación familiar, o bien regresan a la madrugada. Ndèye Fall, del mercado de Soumbédioune, comentó: "En caso de que me quede pescado sin vender, me veo obligada a volver a las tres y media de la mañana para venderlo a las mujeres que lo transforman en productos no perecederos". Si las mujeres poseen el conocimiento y los medios, extienden la vida del pescado fermentándolo, ${ }^{8}$ salándolo, carbonizándolo o ahumándolo.

${ }^{8} \mathrm{La}$ fermentación de pescados medianos se llama guedj, y la de moluscos, yett. 
Fото 2. El mercado de pescado de Soumbédioune.

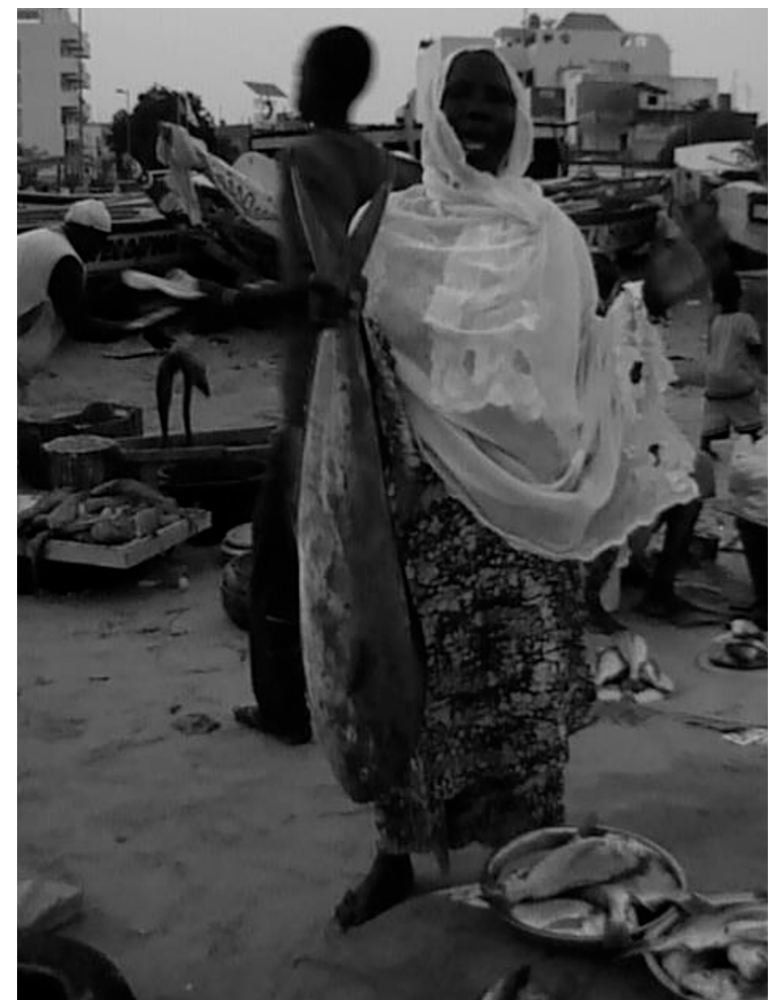

Yacine Ndiaye, vendedora del mercado de Soumbédioune, compartió: "[cuando] las ganancias son insuficientes, en ese caso yo utilizo el dinero para el hogar, y si la situación dura mucho tiempo ya no alcanzo a comprar más pescado para realizar mi trabajo".

\section{Los mercados de legumbres}

El mercado de Tilène se encuentra en la capital y el de Thiaroye en los suburbios; sin embargo, sin importar la lejanía de Thia- 
roye en tiempo y esfuerzo, las mujeres se desplazan a ese lugar para vender o buscar sus mercancías. Astou Fall, vendedora del mercado de Tilène, testimonió lo siguiente: "De vuelta a casa por la tarde paso a Thiaroye para comprar las verduras, llevarlas a casa y venir directamente y temprano al día siguiente para su venta”. De esta manera, ella aprovecha para traer las verduras limpias y no desviarse en el camino, porque el sistema de transporte público es lento en la capital y sujeto al tráfico; además, las verduras limpias son más atractivas para las compradoras.

Las dificultades que atraviesan las vendedoras de legumbres son parecidas a aquellas citadas por las vendedoras de pescado. Amy Seck, entrevistada en el mercado de Tilène, dijo: “A veces vendo a pérdida, sin beneficio alguno; cuando no tengo dinero voy a que me presten la mercancía y después de que la vendo la pago". Fatou Niang, del mismo mercado, señaló: "Cuando no me va tan bien voy con mis amigos a pedir prestado para comprar la mercancía y después reembolso el préstamo”.

Ourèye Bâ, del mercado de Thiaroye, compartió: “A veces uno vende a pérdida, el lugar no es fijo y hay que correr cuando llega la policía”. Binta Barry, del mismo mercado, comentó: "Algunas veces vendo a pérdida o, en algunos casos, dejo los restos de la mercancía o disminuyo su precio y esto no me conviene tanto".

A continuación se abordará el significado del mercado en la vida de estas mujeres; los hombres no son visibles ahí, dada su estancia en el mar o debido a otros trabajos complementarios; tampoco participan en sus redes de apoyo.

\section{El mercado, fuente de ingresos y estrategias}

El precio de las mercancías se encuentra sujeto a la negociación en el mercado, pero no en las tiendas, donde es fijo. La ida al mercado permite un intercambio de saludos y fórmulas de cortesía repetitivas, al igual que un intercambio de discursos, para obtener una disminución en el precio o proveerse de consejos personales. El mercado va más allá del espacio fijo o itinerante de abastecimiento, pues es también el lugar de intercambio de experiencias de vida, consejos y estrategias compartidas. 
Entre esas estrategias destacan el microfinanciamiento a través de las tandas, la venta a crédito, el crédito y el trueque.

La tanda (conocida en francés como tontine) implica un acuerdo entre las mujeres para ahorrar una cantidad determinada: se van sucediendo por turnos para recibir el ahorro; para algunas mujeres es un crédito y para otras, un ahorro, dependiendo del lugar que ocupen en la tanda. Una tanda acumulativa tiene un objetivo común, y la persona que la resguarda recibe el nombre de mère tontine (la madre de las tandas). Marème Thiaw, del mercado de Yoff Tangor, confió que ella ahorra en una tanda.

La venta a crédito es cuando un vendedor facilita la mercancía hasta que, una vez vendida, se paga la cantidad correspondiente; en tanto, el trueque permite el intercambio de mercancías entre vendedoras. Siga Faye, del mercado de Soumbédioune, manifestó lo siguiente: "Si no vendo todo el pescado al menos tengo algo que llevar a casa. No me acerco a un organismo, porque qué tal si me piden cambiarlo por dinero [...] El gobierno está recibiendo ayuda, pero no está distribuyendo el dinero, porque yo no veo parte de esa ayuda".

En síntesis, el mercado es el lugar de gestión femenina, es su fuente de ingresos, su red de financiamiento y de intercambio de alimentos. A continuación se presenta una lectura sobre las relaciones y transcripciones en torno de la preparación de alimentos y su repartición.

\section{Relaciones y transcripciones: el arte de cocinar}

\section{La familia}

Diversos son los elementos que distinguen a la familia en Senegal. El primero de ellos se refiere al aspecto religioso: "95\% de la población senegalesa es musulmana, frente a $4 \%$ católico y $1 \%$ que profesa religiones tradicionales". ${ }^{9}$ En su totalidad, las mujeres que fueron entrevistadas profesan la religión musulmana.

${ }^{9}$ Lucy Creevey, "Islam, Women and the Role of the State in Senegal", Journal of Religion in Africa, vol. xxvI, núm. 3, 1996, p. 268. 
El segundo se refiere a la pertenencia a un grupo étnico. El grupo predominante es la etnia wolof, organizada bajo un sistema de castas que se deriva de uno antiguo que ordena a los grupos de acuerdo con la división social del trabajo y sus funciones. ${ }^{10}$ Las mujeres entrevistadas, en su mayoría, se identifican como miembros del grupo wolof (excepto las vendedoras del mercado de Thiaroye, de origen guineano); ninguna de ellas tiene casta (géer). Los géer no se especializan ni son artesanos, pues tienen libertad para escoger sus actividades económicas (la agricultura, la pesca o la crianza de animales). La familia wolof se rige por un sistema jerárquico, en el que predomina la endogamia (un sistema menos aceptado por los jóvenes), la poligamia y la patrilinealidad.

El tercer elemento se vincula al tamaño, la estructura familiar y el lugar de instalación. Las estructuras familiares "no resguardan únicamente a las familias en sensu stricto, sino que toman en cuenta a los grupos de personas que viven en un lugar común, la mayoría de ellos vinculados por lazos familiares". ${ }^{11}$ Una de las vendedoras entrevistadas señaló que en su casa al menos 30 personas comparten el hogar, y la mayoría de las entrevistadas vive en hogares patrilocales.

La familia se encuentra regida bajo el Código de la Familia. ${ }^{12}$ Este código es importante porque unifica el derecho consuetudinario y la ley religiosa, conocida como la sharia, bajo el rito malikita musulmán.

El Código de la Familia es un código civil que trata de "establecer una ley uniforme para ser aplicada a todos los ciudadanos, sin importar su denominación religiosa[; sin embargo,] incluye algunas variaciones para que los musulmanes opten por una versión del derecho islámico, correspondiente a las disposiciones del Corán". ${ }^{13}$ Estas opciones están vinculadas a

${ }^{10}$ Explicar el sistema de castas o la familia wolof podría ser tema de otro artículo; para mayor referencia véase: Mamadou Diouf, "Essai sur l'histoire du Saalum", $R e$ vue Sénégalaise d'Histoire, vol. 2, núm. 1, 1981, pp. 25-37; Abdoulaye-Bara Diop, La famille wolof: Traditions et changement, París, Karthala, 1985 y, del mismo autor, La société rolof, París, Karthala, 1981.

${ }^{11}$ Thérèse Locoh, Familles africaines, population et qualité de la vie, París, Ceped, 1995, p. 11.

${ }_{12}$ Publicado en el Diario Oficial de la República de Senegal, el 12 de agosto de 1972.

${ }^{13}$ Nadine Sieveking, “We don't want Equality, We want to be given Our Rights: 
la poligamia, a las relaciones de poder, donde los hombres son reconocidos como los jefes de familia (depositarios de la patria potestad, los bienes y la herencia) y los proveedores del hogar, en tanto las mujeres son las garantes del mantenimiento de ese hogar y del cuidado de los miembros que integran la familia.

¿Cómo se distribuyen los espacios compartidos? Las mujeres casadas, que viven en el hogar de sus esposos, comparten los espacios comunes (cocina, sala y comedor) con los demás miembros del hogar y sus coesposas. "Los papeles y las funciones son atribuidos de acuerdo con el sexo, la edad, las relaciones familiares [...] el grado en la casta, el estatus marital, el rango entre las coesposas y así sucesivamente".$^{14}$

Desde pequeña, la niña participa en las actividades domésticas, mientras que los niños juegan; es instruida sobre el papel que deberá desempeñar en un futuro. Cuando las mujeres fueron interrogadas sobre la división sexual del trabajo doméstico, respondieron que una actividad que recae totalmente sobre ellas y sus hijas es la de cocinar. Cuando se interrogó a Ndèye Diop, del mercado de Soumbédioune, sobre si le pide ayuda a sus hijas para realizar el trabajo doméstico, ella contestó: "Sí, a mi hija la más pequeña, porque ella no está dedicada a los estudios”.

Un testimonio como el de Marème Thiaw destaca: "La niña a mi cargo ${ }^{15}$ hace las compras, mientras yo estoy vendiendo en el mercado; así nadie va a esperar o a detenerse el día siguiente". Las labores en los hogares polígamos se rotan entre las esposas. Marème recibe la visita de su marido dos veces a la semana; ella subrayó: "Si sé qué voy a cocinarle a mi marido, soy yo quien le prepara [la comida], si no es la pequeña. Si mi marido viene, yo le preparo su baño, después le doy de comer, le preparo su té y nos vamos a dormir".

En Senegal, el Censo General de Población y Vivienda de 2002 reveló que " $38.1 \%$ de las personas casadas son polígamas.

Muslim Women Negotiating Global Development Concepts in Senegal”, Africa Spectrum, vol. 1, núm. 42, 2007, p. 36.

${ }^{14}$ Fatou Sow, "Family and Law in Senegal: Continuity and Change", en H. Hoodfar (ed.), Shifting Boundaries in Marriage and Divorce in Muslim Communities, dossier especial, vol. 1, Montpellier, Women Living under Muslim Laws, 1996, p. 146.

${ }^{15}$ Es una práctica recurrente que los familiares de otras regiones envíen a sus hijos a la capital con sus familiares, por considerar que en Dakar existen mayores posibilidades de éxito y de asegurarse un apoyo financiero. 
Los hombres polígamos representan 22.5\% y la proporción de mujeres que viven en unión polígama se eleva a $49.8 \%$. La proporción, en cuanto a ellas, es de 2.9 mujeres por hombre polígamo". ${ }^{16}$

Las mujeres entrevistadas viven en familias extensas, organizadas de diferentes maneras al momento de preparar los alimentos. Por ejemplo, Ourèye Bâ testimonió: "Mi hermana y yo hacemos la cocina juntas y la esposa de mi hermano prepara aparte su comida". Cocinar con otro familiar de línea directa es un acto de socialización que permite la visita de estos familiares en el hogar del esposo y una estrategia económica para aligerar los costos de la cocción de los alimentos.

Cocinar en solitario o con otro miembro de la familia permite marcar distancia de los otros familiares y hasta mostrar rechazo y mala relación. Yacine Ndiaye nos confió: "Me llevo bien con mi familia política, excepto con mi cuñado que es un poco complicado [...] su esposa prepara su comida aparte". ¿Acaso la cocina como espacio compartido puede ser apropiada por las mujeres en un hogar extenso?, de eso trata el siguiente subtema.

\section{Símbolos de la cocina}

La cocina es el espacio de las mujeres. Este lugar representa una relación dialéctica en su vida, porque es el lugar de confinamiento y a su vez el espacio de autonomía. En el primer caso, las mujeres no pueden escapar a esta tarea doméstica. Aun si la mujer casada contara con el apoyo de una empleada doméstica, la esposa está a cargo de la supervisión y la preparación de los alimentos. Cuando las mujeres son más maduras se les permite alejarse de esta obligación y apoyarse en las otras mujeres del hogar.

Por otro lado, en la cocina, la mujer puede estar a solas, lejos del escrutinio masculino y de las otras mujeres del hogar compartido. La cocina "no es solamente el lugar donde ella

${ }^{16}$ Agence Nationale de la Statistique et de la Démographie, Rapport National de Présentation des Résultats Définitifs du Troisième Recensement Général de la Population et de l'Habitat (2002), Dakar, ANSD, diciembre de 2006, p. 31. 
prepara el alimento de la familia, sino también, y especialmente para ella, su lugar predilecto, donde ella organiza y conserva los utensilios y los productos de su soberanía en la vida comunitaria". ${ }^{17}$

En la cocina, las mujeres cuentan con utensilios básicos y propios, como un mortero de madera (gueunne) y su mazo (courr), una marmita (tchine), una arrocera (yindée) y una coladera (tamis). Si la presencia de los hombres en la cocina familiar es casi inexistente, fuera del hogar, por soltería o por dedicarse a la venta de alimentos, ellos darán prioridad a la utilización de instrumentos de cocina modernos sobre los tradicionales. Se tiene la creencia de que el uso de los utensilios tradicionales pone en riesgo su virilidad.

La mujer comienza sus tareas en la cocina desde la infancia. A los ocho años, las niñas se inician pelando legumbres y moliendo la mezcla llamada roff, hecha de sal, ajo, cebolla, pimienta, chile y perejil molido; si la economía lo permite se le agrega un cubo Maggi o de una marca genérica. El roff es utilizado cotidianamente en los rellenos del pescado y el pollo.

A los 14 años, las adolescentes se encargan de revisar las cantidades de agua en el arroz y de supervisar la sal en los alimentos. Hacia los 18 años, las jóvenes han aprendido a preparar y encargarse de los alimentos por sí solas; esta independencia implica ya la madurez para encargarse de un hogar propio.

Durante la niñez, las niñas participan en la cocina solamente los fines de semana y los periodos de vacaciones escolares; posteriormente, se van encargando de ella por las tardes hasta quedar totalmente a cargo, en caso de deserción escolar.

\section{Pleitos con todos, excepto con la cocinera}

El mercado es el lugar donde las mujeres se proveen de alimentos para la elaboración de la comida; esto responde a una costumbre y a una estrategia que asegura la calidad y la frescura de

\footnotetext{
${ }^{17}$ Kala-Lobe, "Violation de l'identité culinaire 'negro africaine”, Présence Africaine, núm. 99-100, pp. 204-205, citado por Ramiro Delgado, "Comida y cultura: identidad y significado en el mundo contemporáneo", Estudios de Asia y África, vol. 36(1), núm. 114, 2001, pp. 91-92.
} 
los alimentos en un país donde la población no tiene la capacidad adquisitiva para comprar un refrigerador ni puede garantizar el funcionamiento de éste debido a los constantes cortes de electricidad.

Cocinar es una actividad que se disfruta, forma parte del cortejo durante el noviazgo y asegura la permanencia del esposo en el hogar. Esta actividad tiene sus tiempos y sus rituales. Durante el noviazgo, cocinar promueve a las novias como las esposas idóneas, y una vez casadas les da la tranquilidad de que los maridos no las regresarán al hogar paterno o buscarán una nueva unión. En el caso de los hombres, invitar a su novia a comer fuera de casa o proveer su hogar de comida es señal de que será un hombre comprometido con la alimentación. "Para reproducirse efectivamente, una mujer no solamente necesita la inseminación, sino también la provisión [..., ] un hombre con recursos es preferible a uno sin recursos, independientemente de su atractivo físico". ${ }^{18}$

En el país, en el lenguaje cotidiano, hay dos dichos que reflejan la importancia de la cocina y la ligan (como en varias culturas) a la sexualidad: "Para conservar a tu hombre satisface su vientre y su bajo vientre" y "Una buena esposa sabe ser tan dulce como la miel y un clavo de olor picante en su matrimonio".

Cocinar tiene sus rituales. Antes de iniciar la cocción de los alimentos se pronuncia la fatwa Bismillab(i $)^{19}$ del Corán, la cual inaugura los actos de los musulmanes; hacia las diez y media de la mañana, las mujeres que permanecen en el hogar comienzan la molienda del roff.

Mientras cocinan, las mujeres cantan en voz alta; sus canciones expresan alegría o nostalgia por el esposo que se encuentra fuera del hogar. En la preparación de los alimentos hay una mezcla de conocimientos y sentimientos.

Para que el lector tenga una idea del esfuerzo que requiere la preparación de un platillo tradicional veamos el caso del thieboudienne: una vez que el pescado está limpio de escamas y lavado se rellena con roff. El pescado se cuece primero (o se fríe generosamente en aceite de cacahuate o palma) y, poste-

${ }^{18}$ Fox, "Food and Eating: An Anthropological Perspective", op. cit., p. 11.

19 "En el nombre de Alá". 
riormente, se agrega a un caldo con verduras que ha hervido previamente con un chile entero que sólo da sabor, pero no se come. Después, se coloca el arroz (previamente lavado) en la vaporera, sobre el pescado y sus complementos, y una vez cocidos se sacan y se vierte el arroz; ésta es una estrategia para optimizar recursos ante la escasez del agua y lo costoso del gas (a veces, sustituido o alternado con leña), además de que mejora el sabor, el color y el aroma del arroz.

Las mujeres en la cocina están "entregando amor y afecto, energía y emoción [...] las mujeres transforman la cocina en una creación artística, trabajo de amor que al mismo tiempo manifiesta su afecto y fortalece su autoafirmación”. ${ }^{20}$ En la cocina de las mujeres entrevistadas hay una mezcla del savoir faire, de respeto a las reglas sociales y religiosas. A continuación se señalarán las restricciones en la alimentación.

Los alimentos, entre el presupuesto y lo sagrado

¿Qué tipo de platillos se consumen en los hogares de la capital? Esto depende del presupuesto familiar y de la cotidianidad. El arroz es comprado en grandes cantidades, en sacos de 50 o 100 kilogramos para todo el mes. En tanto, la posición geográfica permite la provisión cotidiana de diferentes tipos de pescado, entre los que destacan el mero (thiouf), el capitán, la carpa, el marlin, el dorado, el atún y la sardina.

En los días de fiesta existe "el propósito ritual de unir a los celebrantes en un acto común de comer con todas sus asociaciones ricamente simbólicas [...] Cocinar un animal completo parece estar reservado únicamente a las ceremonias familiares $\mathrm{u}$ ocasiones festivas". ${ }^{21}$ En encuentros familiares y religiosos, tales como bodas y días del calendario religioso musulmán, ${ }^{22}$ las familias sacrifican un cordero completo y comparten con las familias que no pueden afrontar este gasto.

${ }^{20}$ Ishita Banerjee, "Charla culinaria”, Estudios Sociológicos, vol. xxII, núm. 1, 2004, p. 210.

${ }^{21}$ Fox, "Food and Eating: An Anthropological Perspective", op. cit., pp. 19-20.

${ }^{22}$ Fin del ramadán (Korité), Tabaski o el Gran Magal de Touba (fiesta que celebra el exilio del primer líder de la cofradía muride, Cheikh Amadou Bamba). 
¿Qué tipo de restricciones tiene la comunidad musulmana? $\mathrm{La}$ ingesta de carne de puerco, el consumo de sangre de animales, los alimentos que no sigan el ritual halal y las bebidas alcohólicas o enervantes. Bajo el rito halal, los animales son muertos a través de una incisión que les corta la vena yugular y la carótida, para que así se desangren de manera rápida y el animal muera sin ser maltratado.

El consumo de alcohol no está considerado y las bebidas comunes son las aguas y los jugos de sabores (jamaica con menta, tamarindo, baobab y jengibre); además, se preserva la ceremonia del té (ataya) con menta. ${ }^{23}$ Así como existen prohibiciones en la dieta de los hogares musulmanes, en la mesa existe un código de conducta tácito que debe ser respetado. Se abordará en el siguiente apartado.

\section{Relaciones y transcripciones: la mesa}

\section{Reglas en la mesa}

Las mujeres disponen de gran parte de su tiempo para cocinar; sin embargo, el ritmo agitado de vida de la capital y la economía familiar (dificultad para adquirir los alimentos ante la devaluación y la crisis alimentaria) no permiten la preparación y degustación de todas las comidas en el hogar. Durante el día, las personas consumen en la calle diversos productos de bajo $\operatorname{costo}^{24} \mathrm{o}$ lo que pueden llevar preparado desde casa; lo anterior

${ }^{23}$ El té es el complemento ideal para finalizar una comida copiosa, pero también un pretexto para hacer una "pausa" durante la jornada en la casa, en el trabajo o en la calle, e invitar a conocidos y desconocidos; los utensilios son una tetera y unos vasos pequeños de té; los ingredientes, hojas frescas de menta y azúcar. Esta tradición fue heredada por el mundo árabe; el té es hervido en tres tiempos que asemejan la vida, y se busca que sea espumoso al momento de servirse, por eso se pasa de un vaso al otro de manera repetida. El primer vaso es amargo y simboliza el nacimiento; el segundo es dulce como el amor, y el tercero es mucho más dulce, como en el momento de la muerte, cuando uno se convierte en ancestro.

${ }^{24}$ Entre los cuales hay una diversidad de productos locales e internacionales (huevo cocido por pieza, beignets, nems, fataya, orden de papas a la francesa, baguette preparada conforme el bolsillo del comprador: pan con mayonesa casera, papas a la francesa y cebollas fritas o con espagueti o con un huevo frito o frijoles; arroz solo o con un guisado). 
ha modificado los hábitos alrededor de la comida, ligados en el pasado sólo a la esfera privada y las mujeres, y los ha trasladado en la actualidad a una esfera pública inclusiva.

Los tiempos de comida por la mañana y por la tarde son menos rigurosos que los de la comida nocturna. "Es durante la noche cuando los antepasados regresan al mundo de los vivos para alimentarse [...] Según la creencia, los ancestros están en constante contacto con sus descendientes y el pacto que liga a estos dos mundos pasa generalmente por el acto de comer". ${ }^{25}$

En la mesa, lo primero que prevalece es la hospitalidad, doblemente infundida por la religión musulmana y el concepto de teranga que distingue al país. En segundo lugar se aplica el principio de compartir la comida (seddo en lengua wolof) con familiares, aliados e invitados, y con extraños cuando los anteriores han terminado de comer. En barrios donde existen escuelas coránicas, los alumnos van casa por casa buscando comida.

El hecho de compartir lo mucho o lo poco que se tiene refleja la valoración de las relaciones sociales sobre los bienes materiales; incluso si no existe una comida formal en los demás espacios es común ver a las personas cercanas y extrañas dividir sus alimentos y sus bebidas. La solidaridad es una práctica recurrente y no es bien visto que las personas se aíslen para comer o beber.

Las elecciones relativas a la comida no se basan simplemente en lo que uno come. Comer es el final de un proceso que implica muchos otros aspectos vinculados a la alimentación, como la cocina, los alimentos utilizados y las reglas para su combinación y preparación; la comida y las reglas de etiqueta, las costumbres que rigen qué, con quién, cuándo y dónde se come; tabú y simbolismo vinculados a la alimentación. ${ }^{26}$

Las reglas en la mesa motivan a los comensales a comer de manera conjunta y, al término de la comida, a conversar. Ellos se distribuyen a lo largo de la mesa sentados sobre sillas, o en

${ }^{25}$ Ndoye et al., Évolution des styles alimentaires à Dakar, op. cit., p. 36.

${ }^{26}$ C. Counihan, The Anthropology of food and body. Gender, Meaning and Power, Nueva York-Londres, Routledge, 1999, pp. 19-20, citado por Moira Luraschi, "Food and Identity of the African Diaspora in the Postcolonial Literature", ponencia presentada en ECAS 2011-4 $4^{\text {th }}$ European Conference on African Studies, Upsala, 15-18 de junio de 2011. 
el suelo donde la mesa es un tapete cubierto con un mantel, lo que les permite mayor intimidad y control. El tamaño del tapete se amplía dependiendo del número de invitados.

Según el sexo o la edad se ocupa un lugar específico cuando hombres y mujeres tienen una relación más igualitaria de carácter religioso y étnico. Los miembros de la familia comen juntos; cuando los hombres comen en el comedor y las mujeres y los niños en la cocina se rompen las reglas, pero solamente cuando hay invitados o durante una fiesta religiosa. En la mesa comunitaria, los hombres encabezan y la esposa se coloca al lado suyo; los demás miembros se sientan alrededor, cuidando de no apuntar a los otros con los pies descalzos. ${ }^{27}$

Los niños pequeños tienen el derecho de estar sobre el regazo de sus madres; conforme van creciendo, toman su lugar en la mesa y tienen prohibido levantarse de ella, comer rápido, levantar la mirada o platicar. "La comida es lo más importante que una madre le da a un niño [..., se convierte no solamente en un símbolo, sino en una realidad de amor y seguridad". ${ }^{28}$

El hombre mayor es el primero en comer después de haber pronunciado el Bismillab(i); en tanto, la mujer mayor o anfitriona debe y puede ser llamada "madre", lo que denota su importancia social. El final de la comida se sella con la frase "Alhamdulillab(i)". ${ }^{29}$

\section{La disposición de los alimentos y sus reglas}

En el centro de la mesa se coloca el platón con la comida comunitaria; el uso de los cubiertos o de vajillas no es muy frecuente, lo que permite el contacto directo con los alimentos, siempre teniendo cuidado de usar la mano derecha (la mano izquierda está restringida, porque es utilizada para el aseo personal).

Los hombres son menos diestros que las mujeres para comer con las manos, y para esas ocasiones se les ofrece una cuchara. Cuando el infante ya no es amamantado o se le combina la leche materna con los alimentos sólidos, la madre no usa

\footnotetext{
${ }^{27}$ Es de buena educación descalzarse al entrar a una casa.

${ }^{28}$ Fox, "Food and Eating: An Anthropological Perspective", op. cit., p. 1.

29 "Gracias a Dios".
} 
cucharas para alimentarlo, sino que le hace pequeñas bolitas de arroz, desmenuza el pescado y tritura las verduras para facilitarle la ingesta de la comida. No hay momento de mayor bienestar, cuidado e intimidad que en ésta la primera etapa de vida, cuando los niños son propios y de la comunidad; por eso, la buena comida es una prolongación del amor materno en la etapa adulta.

Si el platón facilita al comensal saber la parte del arroz que le corresponde, esto no resulta claro sobre las verduras, el pescado, el pollo o la carne colocados en el centro, pues es la "madre" quien ejerce su poder y distribuye la comida. $\mathrm{La}$ "madre" reafirma su posición de cuidadora y garante del bienestar de los suyos. Ante los invitados muestra la posición socioeconómica del hogar y consolida la imagen de su esposo y de la familia.

Claude Lévi-Strauss [...] notó cómo nosotros reservamos la comida copiosa para las grandes ocasiones [...] Hay algunas delicias que uno no puede comprar o consumir solo sin sentir un poco de culpa [...] El alimento está destinado para ser compartido y para compartir con aquellos que queremos impresionar. ${ }^{30}$

Alimentar provee de salud interna y de belleza externa. La complexión robusta es señal del buen cuidado; la corpulencia es igual a hermosura, salud, fortaleza, cuidado y amor acumulado.

Las personas casadas no tienen como opción un régimen de dieta. Los hombres casados no pueden negarse a comer la comida que sus mujeres les han preparado con dedicación durante el día. No desean insultar o desanimar a sus mujeres ni tampoco discutir con ellas.

Los cuerpos gruesos en la sociedad senegalesa evidencian el estatus socioeconómico; las mujeres llenas son más atractivas como futuras esposas. En el imaginario social, la silueta redonda es igual a vitalidad y fertilidad, adhesión a la buena comida y una vida desahogada. A mayor edad se promueve el aumento de la talla de las esposas, como ejemplo de la estabilidad familiar, de la plenitud sexual y de la generosidad de sus esposos.

${ }^{30}$ Fox, "Food and Eating: An Anthropological Perspective", op. cit., p. 5. 
Poco a poco, este patrón se ha ido modificando por razones médicas, y otros recursos visibilizan el estatus social, tales como la vestimenta, las alhajas y las fiestas abundantes en viandas y bebidas; sin embargo, la belleza de la mujer es un valor social apreciado y tiene un peso importante en las relaciones sociales; la belleza se integra no sólo de características físicas, sino también de atributos familiares, civiles y religiosos dados. En este contexto, la mujer es sujeto que transforma, administra y conserva los recursos disponibles para asegurar la dieta de los miembros del hogar.

\section{Comentarios finales}

La forma como se cocinan los alimentos en la sociedad es un reflejo de su entorno, de sus estructuras y de las relaciones de poder entre hombres y mujeres. En la capital senegalesa, Dakar, el ritmo de vida y las dificultades económicas han hecho disminuir la preparación de los alimentos en el hogar y abierto las esferas de acción para incluir a hombres y mujeres en la preparación y venta de los alimentos consumidos en la calle, en espacios mixtos.

Sin embargo, en la esfera privada se mantienen los esquemas ligados a la tradición familiar y religiosa, donde las mujeres son las únicas encargadas de las compras, de la preparación de los alimentos y de su repartición en la mesa.

Las mujeres entrevistadas (en los mercados de pescado y de legumbres) dan testimonio de las dificultades que diariamente atraviesan para desempeñar sus labores y enriquecen la visión del mercado como el espacio de autogestión que les permite obtener un ingreso monetario o insumos para asegurar el bienestar de la familia.

Entre las actividades domésticas de la mujer, la cocina ocupa el primer lugar de las tareas que debe desempeñar; sin embargo, la cocina no es sólo un espacio de confinamiento, sino también un espacio que les asegura la visita de familiares, independencia de los demás miembros del hogar y soberanía sobre sus utensilios y la forma en que preparan sus alimentos. 
Al calor del fogón, las mujeres invierten el producto de su esfuerzo físico, de su conocimiento de las combinaciones permitidas y de los rituales, pero sobre todo su amor, vinculado a una cuestión corporal y afectiva.

En la mesa, la mujer recibe el reconocimiento de los familiares y los invitados; su facultad de distribución no se pone en duda, y obliga al lector de estas sutiles transcripciones a repensar las relaciones de poder entre hombres y mujeres alrededor de los alimentos.

Dirección institucional de la autora:

Escuela de Enfermería Helen Keller

Calzada de los Misterios 45

Ex Hipódromo de Peralvillo

06250, México, D.F.

maguilar.escobedo@yahoo.com

\section{Información oral:}

Astou Fall, mercado de Tilène, julio de 2010.

Amy Seck, mercado de Tilène, julio de 2010.

Binta Barry, mercado de Thiaroye, julio de 2010.

Fatou Niang, mercado de Tilène, julio de 2010.

Marème Thiaw, mercado de Yoff, julio de 2010.

Ndèye Diop, mercado de Soumbédioune, julio de 2010.

Ndèye Fall, mercado de Soumbédioune, julio de 2010.

Ourèye Bâ, mercado de Thiaroye, julio de 2010.

Siga Faye, mercado de Soumbédioune, julio de 2010.

Yacine Ndiaye, mercado de Soumbédioune, julio de 2010.

\section{Bibliografía}

Agence Nationale de la Statistique et de la Démographie, Rapport National de Présentation des Résultats Définitifs du Troisième Recensement Général de la Population et de l'Habitat (2002), Dakar, ANSD, diciembre de 2006.

BANERJEE, Ishita, "Charla culinaria", Estudios Sociológicos, vol. XXII, núm. 1, 2004, pp. 203-212. 
Creevey, Lucy, "Islam, Women and the Role of the State in Senegal”, Journal of Religion in Africa, vol. xxvi, núm. 3, 1996, pp. 268-307. Cribier, Jacqueline, Martine Dreyfus y Mamadou Gueye, Léebu, proverbes wolof, París, Edicef, 1986.

Delgado, Ramiro, "Comida y cultura: identidad y significado en el mundo contemporáneo", Estudios de Asia y África, vol. 36(1), núm. 114, 2001, pp. 83-108.

Diop, Abdoulaye-Bara, La famille wolof: Traditions et changement, París, Karthala, 1985.

Diop, Abdoulaye-Bara, La société rolof, París, Karthala, 1981.

Diouf, Mamadou, "Essai sur l'histoire du Saalum”, Revue Sénégalaise d'Histoire, vol. 2, núm. 1, 1981, pp. 25-37.

Fox, Robin, "Food and Eating: An Anthropological Perspective", Oxford, Social Issues Research Centre, 2003. [www.sirc.org/ publik/foxfood.pdf, consultado el 13 de octubre de 2013.]

LocoH, Thérèse, Familles africaines, population et qualité de la vie, París, Ceped, 1995.

LuRASCHI, Moira, "Food and Identity of the African Diaspora in the Postcolonial Literature", ponencia presentada en ECAS 2001-4 ${ }^{\text {th }}$ European Conference on African Studies, Upsala, 15-18 de junio de 2011.

NDOYE, Fatou et al., Évolution des styles alimentaires à Dakar, Montpellier, CIRAD, 2001.

ScoTT, Joan, "Gender: A Useful Category of Historical Analysis", The American Historical Review, vol. 91, núm. 5, pp. 1053-1075.

SiEvering, Nadine, "We don't want Equality, We want to be given Our Rights: Muslim Women Negotiating Global Development Concepts in Senegal", Africa Spectrum, vol. 1, núm. 42, 2007, pp. 29-48.

Sow, Fatou, "Family and Law in Senegal: Continuity and Change", en H. Hoodfar (ed.), Shifting Boundaries in Marriage and Divorce in Muslim Communities, dossier especial, vol. 1, Montpellier, Women Living under Muslim Laws, 1996, pp. 142-157. 
